\title{
The Effect of Intramuscular Administration of Glutathione as Antioxidant on Semen analysis parameters of Infertile Patients Affected with Oligoasthenozoospermia
}

\author{
*Basim Khamees Gootee \\ **Deyia Abed Oda Jazaa \\ *Thi-Qar University - College of Science - Department of Biology \\ **Thi-Qar University - College of Nursing - Department of Basic Sciences
}

\begin{abstract}
This study was designed to evaluate the effect of intramuscular administration of Glutathione (100, 200, 300 $\mathrm{mg} /$ person) daily for 3 months on seminal fluid analysis parameters prepared by simple layering technique and centrifugation swim up technique in infertile subjects affected with oligoasthenozoospermia. Thirty infertile men enrolled in this study and semen samples were analyzed before and after injection with Glutathione and semen processed by standard semen parameters. Furthermore, sperm concentration, sperm motility, progressive sperm motility, sperm agglutination, and normal sperm morphology were evaluated according to standard WHO criteria (2010). For preparation technique, sperm prepared and incubated for 30 minute in $5 \% \mathrm{CO}_{2}$ at $37^{\circ} \mathrm{C}$. The results of the present study indicate a highly significant $(\mathrm{P}<0.001)$ differences in all sperm functions after injection with Glutathione in all infertile patients and concluded that sperm functions improved and enhanced whenever increase the dose of antioxidants and the simple layering technique gave the best results as compared with centrifugation swim up technique. Further studies are recommended to assess the detrimental effect of CSUT on sperm DNA damage and embryo quality after in vitro fertilization and embryo transfer (IVF-ET).
\end{abstract}

\section{تاثير اعطاء الـ Glutathione عن طريق العضلة كمضاد اكسدة على متغيرات السائل المنوي لمرضى العقم المصابين بمتلازمة قلة حركة النطف وعددها}

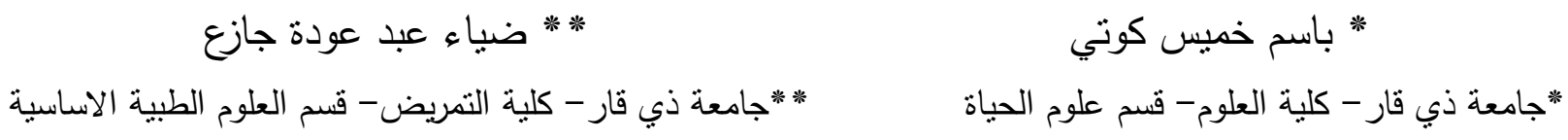

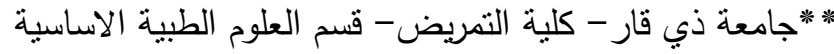

$\underline{\text { الخلاصة }}$

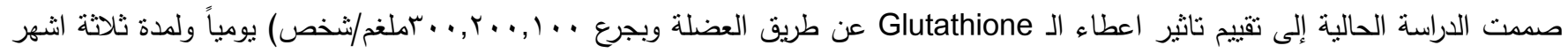
على متغيرات تحليل السائل المنوي باستعمال النظرية الطباقية البسيطة والنبذ المركزي لمرضى العقم المصابين بمنلازمة قلة حركة النطف وعددها. تضمنت

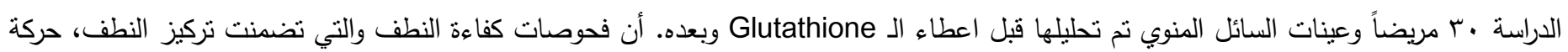

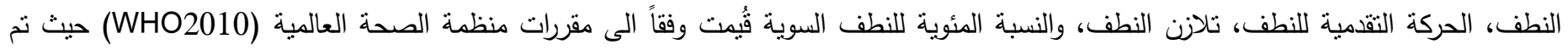

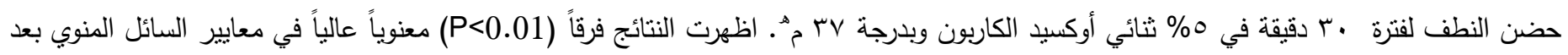

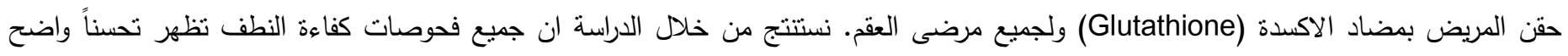
وملحوظ كلما ازدادت جرعة مضاد الاكسدة كما ان النظرية الطباقية البسيطة لتحضير السائل المنوي اعطت افضل النتائج مقارنة بطريقة النبذ المركزي. 


\section{نوصي في الدراسات المستقلية بتقييم التاثير الضار باستعمال طريقة النبذ المركزي في ضرر الـ DNA ونوعية التطورات الجنينية بعد اجراء تقنيات الاخصاب الخارجي ونقل الاجنة.}

\section{Introduction}

The successive beginning of assisted reproduction in human, scientists and clinicians were more advice to improve sperm separation techniques as percentage of andrological cases increased rapidly (1). However, the increasing number of men showing poor semen quality encouraged the development of a wide array of different laboratory techniques focusing on selection and enrichment of motile and functionally competent spermatozoa from ejaculate (2). The methods were developed to improve sperm functions like motility, protected sperm functions, and reduced detrimental effects of environmental impact like reactive oxygen species (ROS) (3). Finally, the ideal sperm separation technique should (a) be quick, easy and cost-effective, (b) isolate as much motile spermatozoa as possible, (c) not cause sperm acrosomal damage or non physiological alterations of separated sperm cells, (d) eliminate dead spermatozoa and other cells, including leukocytes and bacteria, (e) eliminate toxic or bioactive substances like decapacitation factors or ROS, and (f) allow processing of larger volumes of ejaculates (4The ROS are free radicals that play a significant role in many of sperm physiological processes such as capacitation, hyperactivation, and sperm-oocyte fusion (5). However, they also trigger many pathological processes in male reproductive system, and these processes have been implicated in cancers of the bladder and prostate, as well as in male infertility (6). Moreover, the sperm plasma membrane contains lipids in the form of polyunsaturated fatty acids, which are vulnerable to attack by ROS. The ROS, in the presence of polyunsaturated fatty acids, triggers a chain of chemical reactions called lipid peroxidation (7). ROS can also damage DNA by causing deletions, mutations, and other lethal genetic effects (8). It is difficult to block the oxidative stress (OS) induced injury to cells or tissues because ROS are continuously produced by cellular aerobic metabolism (9). There are two main sources of ROS in semen: leukocytes and immature spermatozoa and leukocytes are considered to be primary source (10). Leukocytes, particularly neutrophils and macrophages, have been associated with excessive ROS production that ultimately leads to sperm dysfunction (11). Spermatozoa produce ROS mainly when a defect occurs during spermiogenesis that results in retention of cytoplasmic droplets (12). The two main sites of ROS production are the mitochondrion and the sperm plasma membrane. The mitochondrion is the powerhouse of respiration. Hence, it is the major site of ROS generation, which is produced through nicotinamide adenine dinucleotidedependent oxido-reductase pathway (13). When levels of ROS engulf the body's antioxidant defence system, oxidative stress (OS) occurs. OS is a condition in which the elevated levels of ROS damage cells, tissues, or organs and ROS can also damage DNA by causing deletions, mutations, and other lethal genetic effects. It is difficult to block the OS induced injury to cells or tissues because ROS are continuously produced by cellular aerobic metabolism (14). Antioxidants are the main defence against OS induced by free radicals. There are prevention antioxidants and scavenger antioxidants. Prevention antioxidants such as metal chelators and metal-binding proteins block the formation of new ROS, whereas scavenger antioxidants remove the ROS that have already formed (15).Glutathione play an important role in sperm metabolism and antioxidative defence, it is a natural, highly effective reducing agent, and this substance has been tried as a tool to treat male infertility. There are significant increases in sperm motility, percentage of progressive motility, and normal sperm morphology for in vitro treatment of spermatozoa with glutathione during sperm separation (16). Following swim-up preparation of human spermatozoa in the presence of glutathione found an improved acrosome reaction and 24 hours-motility on the same level as for Percoll@ gradient centrifugation and suggest that glutathione has a therapeutic potential (17). In contrast, another author provided data indicating that this drug has no significant effect on progressive motility, neither by itself, nor in combination with hypotaurine. However, the treatment still afforded a significant protection against ROS-induced DNA damage (18).

\section{Materials and Methods}

\section{Subjects}

Thirty infertile couples were enrolled in this study and semen samples were obtained from Al-Hussein Teaching Hospital hi-qar health directorate/laboratories section. The mean age of infertile subjects was $31.35 \pm$ 0.66 years old with range from 18-49 years and duration of infertility was $5.66 \pm 0.33$ years with range 
from 2-16 years. The semen samples were collected by masturbation after 3-5 days abstinence and allow liquefying at $37^{\circ} \mathrm{C}$ in $5 \% \mathrm{CO}_{2}$ for 30 minutes and evaluated before and after in vitro sperm preparation and treatment with glutathione. Sperm function tests including sperm concentration, sperm motility, progressive sperm motility, sperm agglutination, and normal sperm morphology were evaluated according to WHO criteria.

\section{Semen preparation techniques}

\section{(a) Simple layering technique}

The semen was prepared by using $1 \mathrm{ml}$ of prepared culture medium was added to test tube, and then $1 \mathrm{ml}$ of liquefied semen was layered beneath a culture medium. After incubation for 30 minute in $5 \% \mathrm{CO}_{2}$ at $37^{\circ} \mathrm{C}$, $10 \mu 1$. of the mixture was aspirated by pasture pipette and examined under light microscope at $400 \mathrm{X}$ magnification for assessment parameters of sperm functions in infertile patients.

\section{(b) Centrifugation swim-up technique}

One of the two portions of liquefied semen $(1 \mathrm{ml})$ was diluted and mixed gently with $1 \mathrm{ml}$ of culture medium by a Pasteur pipette for a several times and run in a centrifuge at $2250 \mathrm{rpm}$ for 6 minutes. Then after supernatant was discarded and $1 \mathrm{ml}$ of culture medium was added to pellet with care and again incubated for 30 minute. Then, a drop (10 $\mu 1$.) was taken and put on a slide and cover with a cover slip and examined at a microscope under 400X objective for assessment of sperm functions.

\section{(c) Statistical analysis of the data}

Statistical analysis was performed with the SPSS version 12.00 (1998) by Statistical Package for Social Sciences Software. The data analysis was done using paired sample t-test to assess statistical differences in results of SFTs. Mean and standard error of mean (S.E.M) was obtained from crude data to compare between seminal fluid analysis parameters. P-value < 0.05 was used as a level of statistically significant.

\section{Results}

After sperm processing using culture medium prepare with simple layering and centrifugation swimup technique and treatment with glutathione, sperm concentration and sperm agglutination were significantly decreased $(\mathrm{P}<0.01)$ as compared to preprocessing, while sperm motility (\%), progressive sperm motility (\%), normal sperm morphology (\%), were significantly $(\mathrm{P}<0.01)$ increased post-in vitro sperm processing as compared to pre-processing (Table $1,2$ and 3$)$.

Table (1) In vitro sperm processing using simple layering and centrifugation swim-up technique in

oligoasthenozoospermic patients injected with $100 \mathrm{mg}$ of glutathione intramuscularly in first months.

\begin{tabular}{|c|c|c|c|c|}
\hline \multirow{2}{*}{ Parameiten } & \multicolumn{2}{|c|}{ Simple byeriana sechniayse } & \multicolumn{2}{|c|}{ Cestriftegatian swies up tochnique } \\
\hline & Pre-treated & Poot-ireated & Pre-treated & Post-beated \\
\hline 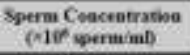 & $40.35+6.313$ & $22.73+3.65$ * & $41.90 \pm 3.244$ & $27.55+3,12 \cdot$ \\
\hline $\begin{array}{c}\text { Sperm } \\
\text { Motiloy (Os) }\end{array}$ & $51.00=2.55 \mathrm{~b}$ & $76.60 \pm 2.07 \cdot$ & $54,00 \div 2.42 \mathrm{~b}$ & $79.25+2.15$ \\
\hline 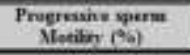 & $31.90=1.66 \mathrm{~b}$ & $54.35 \pm 1.43 \cdot$ & $37,90 \pm 1.93 b$ & $58.35+2.20^{\circ}$ \\
\hline $\begin{array}{c}\text { Sperm } \\
\text { Agalutinatiea (96) } \\
\end{array}$ & $12.50 \pm 2.403$ & $0.00 \pm 0,00 \cdot$ & $14.0002 .13 \mathrm{~s}$ & $0.00<0.606$ \\
\hline 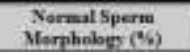 & $44.50+3.20 b$ & $80.25 \pm 2.00 \cdot$ & $49.50+2.536$ & $33.25+2.05 \%$ \\
\hline
\end{tabular}

Values are Mean \pm S.E.M

a: means a highly significance $(\mathrm{P}<0.01)$ different from pre-treatment with glutathione No. of infertile patients $=30$ for both layering and centrifugation technique Mean of age \pm S.E.M for infertile subjects prepare with simple layering technique $(30.05 \pm 4.87$ years) Mean of age \pm S.E.M for infertile subjects prepare with centrifugation technique $(31.75 \pm 6.10$ years)

Table (2): In vitro sperm processing using simple layering and centrifugation swim-up technique in

oligoasthenozoospermic patients injected with $200 \mathrm{mg}$ of glutathione intram uscularly in second months.

\begin{tabular}{|c|c|c|c|c|}
\hline \multirow{2}{*}{ Parameten } & \multicolumn{2}{|c|}{ Simple byeritig tochaigae } & \multicolumn{2}{|c|}{ Ceatrifugatioe swie-up techniqu } \\
\hline & Pre-treated & Post treated & Pre treated & Post-trated \\
\hline $\begin{array}{l}\text { Sperm Ceacentratios } \\
\text { ( } \times 10^{6} \text { sperm inl) }\end{array}$ & $3.22+4.21^{*}$ & $26.51 \neq 2.45$ & $53.75 \pm 3.20^{\circ}$ & $27.54 \div 2.10^{3}$ \\
\hline $\begin{array}{c}\text { Sperm } \\
\text { Motility (\%) } \\
\end{array}$ & $60.00 \pm 2.55 k$ & $72.63+2.04 \cdot$ & $54.00 \pm 2.42^{\circ}$ & $79.25 \div 2.15$ \\
\hline $\begin{array}{c}\text { Progressive sperm } \\
\text { Matility }(\%)\end{array}$ & $33.53 \pm 1.42^{t}$ & $52.55 \div 1.30$ & $29.12+1.93^{k}$ & $52.65+2.23$ \\
\hline $\begin{array}{c}\text { Sperm } \\
\text { Agplutioatiun (\%) }\end{array}$ & $10.54+2.30^{\circ}$ & $0.00 \pm 0.00 \quad+$ & $12.23 \pm 2.13^{*}$ & $0.00 \pm 0.00$ \\
\hline $\begin{array}{l}\text { Normal Sperm } \\
\text { Merpbologe (4) }\end{array}$ & $52.32+3.12^{2}$ & $84.30=2.23$ & $58.13 \pm 2.54^{6}$ & $57.15 \div 2.03=$ \\
\hline
\end{tabular}

Values are Mean \pm S.E.M

a: means a highly significance $(\mathrm{P}<0.01)$ different from pre-treatment with glutathione No. of infertile patients $=30$ for both layering and centrifugation technique Mean of age \pm S.E.M for infertile subjects prepare with simple layering technique $(30.05 \pm 4.87$ years) Mean of age \pm S.E.M for infertile subjects prepare with centrifugation technique $(31.75 \pm 6.10$ years) 
Table (3): In vitro sperm processing using simple layering and centrifugation swim-up technique in

oligoasthenozoospermic patients injected with $300 \mathrm{mg}$ of glutathione intramuscularly in third months.

\begin{tabular}{|c|c|c|c|c|}
\hline \multirow{2}{*}{ Paramuten } & \multicolumn{2}{|c|}{ Simple layering technique } & \multicolumn{2}{|c|}{ Centrifiugation swim-ap techning } \\
\hline & Pretreated & Post-troated & Pretreated & Post-treated \\
\hline 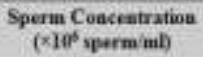 & $40.35+6.31^{*}$ & $22.75+3.65$ & $41.90=3.24^{2}$ & $27.55 \pm 2.14^{5}$ \\
\hline $\begin{array}{c}\text { Sperm } \\
\text { Matlity (5) }\end{array}$ & $51.00+2.55$ & $76.60 \div 2.07$. & $54.00+2.42$ & $54.25 \div 2.15$ * \\
\hline $\begin{array}{l}\text { Progressive sperm } \\
\text { Alatling (\%) }\end{array}$ & $31.90=1.66^{\circ}$ & $54.95 \pm \mathrm{L}, 43$ & $37.12 \pm 1.936$ & $62.35+2.20 \times$ \\
\hline $\begin{array}{c}\text { Spenis } \\
\text { Azglatiation (6) } \\
\end{array}$ & $12.50 \div 2.40^{2}$ & $0.00 \pm 0.00=$ & $14.00 \div 2.13^{4}$ & $0.00+0.00 \mathrm{~B}$ \\
\hline $\begin{array}{l}\text { Yermal Sperim } \\
\text { Merphologe (5e) }\end{array}$ & $44.50 \times 3.26^{\circ}$ & $50.25+2.09$ & $49.50 \div 2.53$ & $88.25+2.166^{*}$ \\
\hline
\end{tabular}

Values are Mean \pm S.E.M

a: means a highly significance $(\mathrm{P}<0.01)$ different from pre-treatment with glutathione No. of infertile patients $=30$ for both layering and centrifugation technique Mean of age \pm S.E.M for infertile subjects prepare with simple layering technique $(30.05 \pm 4.87$ years) Mean of age \pm S.E.M for infertile subjects prepare with centrifugation technique $(31.75 \pm 6.10$ years)

\section{Discussion}

The markedly reduction in sperm concentration and sperm agglutination was observed following both sperm processing techniques after injection intramuscularly with glutathione for all infertile men. These results may be due to beneficial effect of preparation technique by removal of dead, immotile spermatozoa, and semen debris in such away only superior quality motile spermatozoa were harvested and unfortunate quality spermatozoa (19). Conversely, the results indicate that sperm agglutination is not specifically immune reaction; it may be due to the cytotoxic materials which secreted from the inflammatory cells which causes clumping and agglutination. In addition, sperm agglutination either specific or non specific causes sperm clustering which prevent the sperm motility and activity (20). The percentages of sperm motility, progressive sperm motility, and normal sperm morphology were significantly increased after sperm processing. Really, the enhanced sperm functions were a normal response for sperm biology after removal of seminal plasma and sperm agglutination by sperm preparation techniques (21). The best improvement in sperm function was achieved by using simple layer technique as compared to centrifugation swim-up techniques. The selection of sperm preparation methods depend on quality of ejaculates. The ejaculates with ROS production by spermatozoa and leukocytes should not be separated by centrifugation method due to severely damage the spermatozoa (22). When semen samples were prepared by centrifugation, functional spermatozoa can come into close cell-to-cell contact with defective sperm, leukocytes, and cell debris contained by centrifugation force causing massive oxidative damages of sperm plasma membrane via production of very high levels of ROS by pelleting of semen with impairment of sperm functions and decrease in normally chromatin-condensed spermatozoa (23). However, problem caused by ROS can resolve by performed directly from the liquefied semen underneath an overlay of culture medium and aspirate directly from the interface region with total number of spermatozoal recovery (24). Also, the centrifugation force adversely affects sperm motility and impairment of acrosome reaction, sperm plasma membrane in men with abnormal and normal semen analyses in comparison to density gradient centrifugation (25). It was reported that common laboratory factors like centrifugation, washing, temperature fluctuation, and processing delay harmfully affect response pattern of human spermatozoa both positively and negatively due to direct influence of laboratory interventions on cytoskeletonassemblies(26). Spermatozoaare articularly susceptible to the damage induced by excessive ROS because their plasma membranes contain large quantities of polyunsaturated fatty acids and their cytoplasm contains low concentrations of scavenging enzymes (27). In addition, the intracellular antioxidant enzymes cannot protect the plasma membrane that surrounds the acrosome and the tail, forcing spermatozoa to supplement their limited intrinsic antioxidant defenses by depending on the protection afforded by the seminal plasma (28). The use of specific sperm preparation techniques has greatly reduced the oxidative stress associated with sperm handling and cryopreservation. Sperm separation techniques significantly reduce the level of ROS by removing leukocytes, which are the major source of ROS (29). The spermatozoa are affected in different ways by OS; there are sufficient antioxidant protections that can decrease the progressive damage. However, when an imbalance exists between levels of ROS and the natural antioxidant defences, various measures can be used to protect spermatozoa against the OS-induced injury (30). In vitro supplements used during sperm 
preparation and assisted reproductive technique also help to protect spermatozoa against ROS. Moreover, adding antioxidants to culture media neutralizes ROS produced by the leukocytes and immature spermatozoa and improves sperm-oocyte fusion (31). It has been found that adding glutathione and hypotaurine protects spermatozoa against oxidative damage induced by $\mathrm{H}_{2} \mathrm{O}_{2}$ (32). Glutathione is the most abundant antioxidant found in the body. It plays an important role in protecting lipids, proteins, and nucleic acids against oxidative damage. It combines with vitamin $\mathrm{E}$ and selenium to form glutathione peroxidase enzyme. However, Glutathione therapy significantly increased sperm motility, particularly forward progressive motility (33).

\section{References}

1. Edwards RG., Steptoe PC. and Purdy JM. (1980): Establishing full term human pregnancies using cleaving embryos grown in vitro. Br. J. Obstet. Gynaecol. 87:737-756.

2. Mahadevan M. and Baker G. (1984): Assessment and preparation of semen for in vitro fertilization. In: Clinical In vitro Fertilization Edited by: Wood C, Trounson A. Springer-Verlag, Berlin: 83-97.

3. Zavos PM., Abou-Abdallah M., Aslanis P., Correa JR. and Zarmakoupis-Zavos PN. (2000): Use of the multi-ZSC one-step standardized swim up method: recovery of high-quality spermatozoa for intrauterine insemination or other forms of assisted reproductive technologies. Fertil. Steril. 74:834-835.

4. Lopata A., Brown JB., Leeton JF., Talbot JM. and Wood C. (1978): In vitro fertilization of preovulatory oocytes and embryo transfer in infertile patients treated with clomiphene and human chorionic gonadotropin. Fertil. Steril. 30:27-35.

5. Aitken RJ. and Clarkson JS.(1988): Significance of reactive oxygen species and antioxidants in defining the efficacy of sperm preparation techniques. J. Androl. 9:367-376.

6. Mbizvo MT., Johnson RC. and Baker GHW. (1993): The effect of the motility stimulants, caffeine, pentoxifylline, and 2-deoxyadenosine on hyperactivation of cryopreserved human sperm. Fertil. Steril. 59:1112-1117.

7. Ahmadi A. and Soon-Chye NG. (1992): The single sperm curling test. a modified hypo-osmotic swelling test, as a potential technique for the selection of viable sperm for intracytoplasmic sperm injection. Fertil. Steril. 68: 346-350.

8. Mahadevan MM., Trounson AO. and Leeton JF. (1983): The relationship of tubal blockage, infertility of unknown cause suspected male infertility, and endometeriosis to success of in vitro fertilization and embryo transfer. Fertil. Steril. 40:755-762.

9. World Health Organization (WHO) (1999): Laboratory Manual for the Examination of Human Semen and Semen-Cervical Mucus Interaction, 4th ed. Cambridge, Cambridge University Press UK. Pp.8-11.

10. Verheyen C., Joris H., Crits K., Nagy Z., Tournaye H. and Van Steirteghem A. (1997): Comparison of different hypo-osmotic swelling solutions to select viable immotile spermatozoa for potential use in intracytoplasmic sperm injection. Hum. Reprod. Update. 3:195-203.

11. Makkar G., Ng HY., Yeung SB. and Ho PC. (1999): Comparison of two colloidal silica-based sperm separation media with a non-silica-based medium. Fertil. Steril. 72:796-802.

12. Agarwal A., Hamamah S. and Shekarriz M. (1994): Reactive oxygen species and fertilizing capacity of spermatozoa. Contracept. Fertil. Sex. 22:327-330.

13. Agarwal A., Nallella KP., Allamaneni SS. and Said TM. (2004): Role of antioxidants in treatment of male infertility: an overview of the literature. Reprod. Biomed. Online. 8:616-627.

14. Agarwal A. and Said TM. (2004): Carnitines and male infertility. Reprod. Biomed. Online. 8:376384.

15. Depuydt C., Zalata A., Christophe A., Mahmoud A. and Comhaire F. (1998): Mechanisms of sperm deficiency in male accessory gland infection. Andrologia. 30 (Suppl.1):29-33.

16. Di Mascio P., Kaiser S. and Sies H. (1989): Lycopene as the most efficient biological carotenoid singlet oxygen quencher. Arch. Biochem Biophys. 274:532-538.

17. Donnelly ET., McClure N. and Lewis SE.(1999): Antioxidant supplementation in vitro does not improve human sperm motility. Fertil. Steril. 72:484-495.

18. Donnelly ET., McClure N. Lewis SE. (2000): Glutathione and hypotaurine in vitro: effects on human sperm motility, DNA integrity and production of reactive oxygen species. Mutagenesis. 15:61-68. 
19. Ford WC. and Whittington K.(1998): Antioxidant treatment for male subfertility: a promise that remains unfulfilled. Hum. Reprod. 13:1416-1419.

20. Fraga CG., Motchnik PA., Wyrobek AJ., Rempel DM. and Ames BN. (1996): Smoking and low antioxidant levels increase oxidative damage to sperm DNA. Mutat. Res. 351:199-203.

21. Garrido N., Meseguer M., Simon C., Pellicer A. and Remohi J. (2004): Pro-oxidative and antioxidative imbalance in human semen and its relation with male fertility. Asian. J. Androl. 6: 59-65.

22. Gate L., Paul J., Ba GN., Tew KD. and Tapiero H. (1999): Oxidative stress induced in pathologies: The role of antioxidants. Biomed. Pharmacother. 53: 169-180.

23. Sikka SC. (2001): Relative impact of oxidati stress on male reproductive function. Curr. Mea. Chem. 8:851-862.

24. Darley-Usmar V., Wiseman H. and Halliwell B. (1995): Nitric oxide and oxygen radicals: a question of balance. FEBS. Lett. 369:131-135.

25. Wu TP., Huang BM., Tsai HC., Lui MC. and Liu MY. (2004): Effects of nitric oxide on human spermatozoa activity, fertilization and mouse embryonic development. Arch. Androl. 50:173179.

26. Garrido N., Meseguer M., Simon C., Pellicer A. and Remohi J. (2004): Pro-oxidative and antioxidative imbalance in human semen and its relation with male fertility. Asian. J. Androl. 6:59-65.

27. Gomez E., Buckingham DW., Brindle J., Lanzafame F., Irvine DS. and Aitken RJ.(1996): Development of an image analysis system to monitor the retention of residual cytoplasm by human spermatozoa: correlation with biochemical markers of the cytoplasmic space, oxidative stress, and sperm function. J Androl. 17:276-287.

28. Aitken RJ., Buckingham DW. and West KM. (1992): Reactive oxygen species and human spermatozoa: analysis of cellular mechanisms involved in luminol-and lucigenin-dependent chemiluminescence. J. Cell. Physiol. 151:466477.

29. Thomas J., Fishel SB., Hall JA., Green S., Newton TA. and Thornton SJ. (1997): Increased polymorphonuclear granulocytes in seminal plasma in relation to sperm morphology. Hum. Reprod. 12:2418-2421.
30. Wolff H. (1995): The biologic significance of white blood cells in semen. Fertil. Steril. 63:1143-1157.

31. Lenzi A., Culasso F., Gandini L., Lombardo F. and Dondero F. (1993): Placebocontrolled, double-blind, cross-over trial of glutathione therapy in male infertility. Hum. Reprod. 8:16571662.

32. Griveau JF. and Le Lannou D.(1994): Effects of antioxidants on human sperm preparation techniques. Int. J. Androl. 17:225-231.

33. Quinn P., Lydic ML., Ho M., Bastuba M., Hendee F. and Brody SA. (1998): Confirmation of the beneficial effects of brief coincubation of gametes in human in vitro fertilization. Fertil. Steril. 69:399-402. 